\title{
¿Cuál es el mejor método de analgesia postoperatoria para artroplastía de cadera?
}

\author{
Ojeda DE. ${ }^{1}$, Monsalve V. ${ }^{2}$, Palma F. ${ }^{2}$, Demetrio B. ${ }^{1}$, Cisternas P. ${ }^{1}$ \\ 1 Clínica Dávila, Santiago, Chile. \\ 2 Universidad de Los Andes, Santiago, Chile.
}

Introducción: La artroplastía de cadera requiere de una analgesia postoperatoria con la eficacia suficiente para posibilitar una kinesioterapia precoz e intensiva en pacientes ancianos y portadores de múltiples patologías. Se ha recomendado el uso escalonado de analgésicos no opioides más opiáceos endovenosos, morfina intratecal (MIT) o bloqueos regionales[1] (B), sin embargo, no existe certeza basada en la evidencia de cual técnica constituye la mejor intervención[2]. Se decidió entonces investigar cual método analgésico era más eficaz.

Material y Métodos: Se realizó un estudio observacional de tipo cohorte retrospectiva que incluyó a todos los pacientes sometidos a artroplastía de cadera desde el año 2015 hasta el 2018. La analgesia tradicional (T) con opiáceos endovenosos fue la referencia con la cual se compararon MIT y B.

Se utilizó análisis tiempo-evento, (Kaplan-Meier y regresión de Cox). Se consideró como tiempo de falla el transcurrido hasta la primera administración del analgésico de rescate.

Resultados: Se obtuvo información de 412 pacientes, quienes recibieron en un $87 \%$ MIT, en un $10 \%$ T y en un 3\% B (Bloqueo del Plexo Lumbar). Estos grupos diferían entre sí, siendo T el con mayor proporción de ancianos, mujeres, fractura de cadera y uso de anestesia general. El análisis multivariado se ajustó por las variables confundentes de relevancia: Edad, capacidad funcional, dosis de Bupivacaína intratecal y uso de anestesia general. Se demostró que MIT disminuía en un 56\% el riesgo de dolor: Hazard Ratio: 0,44 [0,23-0,82]; $p=0,009$, no así B: Hazard Ratio 0,64 $[0,27-1,53] ; \mathrm{p}=0,320$, (Figura 1). La duración de la analgesia se aprecia en la Tabla adjunta. La MIT se asociaba a retención urinaria $(28,2 \%, \mathrm{p}=0,002)$ y náuseas/vómitos $(26,3 \% ; \mathrm{p}=0,087)$, Figura 2.

Conclusión: La morfina intratecal proveyó una mejor analgesia postoperatoria en artroplastía de cadera, a expensas de una mayor incidencia de efectos secundarios.

https://doi.org/10.25237/congresoclasa2019.02 